OPEN ACCESS

Edited by:

Vesna Bjegovic-Mikanovic, University of Belgrade, Serbia

Reviewed by: Margo Bergman, University of Washington Tacoma, United States

Tetine Sentell,

University of Hawaii, United States Lijana Zaletel-Kragelj,

University of Ljubljana, Slovenia

*Correspondence:

Ervin Toci

ervintoci@yahoo.com

Specialty section:

This article was submitted to Public Health Education and

Promotion,

a section of the journa Frontiers in Public Health

Received: 12 February 2020

Accepted: 09 July 2020

Published: 18 August 2020

Citation:

Dika Q, Duli M, Burazeri G, Toci D, Brand $H$ and Toci $E$ (2020) Health Literacy and Blood Glucose Level in Transitional Albania.

Front. Public Health 8:405. doi: 10.3389/fpubh.2020.00405

\section{Health Literacy and Blood Glucose Level in Transitional Albania}

\author{
Qamil Dika ${ }^{1,2}$, Marsida Duli ${ }^{2}$, Genc Burazeri ${ }^{2,3}$, Dorina Toci $^{2}$, Helmut Brand ${ }^{3}$ and \\ Ervin Toci $^{2 *}$
}

${ }^{1}$ Department of Sports Medicine, University of Sports, Tirana, Albania, ${ }^{2}$ Faculty of Medicine, University of Medicine, Tirana, Albania, ${ }^{3}$ Department of International Health, School CAPHRI (Care and Public Health Research Institute), Maastricht University, Maastricht, Netherlands

Aim: Our aim was to assess the independent association between blood glucose level and health literacy $(\mathrm{HL})$ adjusting for many socio-demographic characteristics and body mass index (BMI) in an adult population in Albania, a transitional country in the South Eastern Europe.

Methods: A cross-sectional study was carried out in Tirana in 2012-2014 including a population-based sample of 1,154 individuals aged $\geq 18$ years ( $57 \%$ women; mean age: $45.5 \pm 16.4$ years; response rate: $88.6 \%$ ). HL was assessed by use of HLS-EU-Q instrument. Blood glucose level was measured in a fasting state by use of rapid finger stick method. Information on socio-demographic characteristics was collected, and BMI was calculated based on measurement of height and weight in all participants. General Linear Model (GLM) and binary logistic regression were used to assess the independent association of blood glucose level and $\mathrm{HL}$ adjusting for all socio-demographic factors and BMl.

Results: One-third of participants had pre-diabetes (100-125.9 mg/dl) and further $11 \%$ had diabetes ( $\geq 126 \mathrm{mg} / \mathrm{dl}$ ) based on the measured blood glucose level. In fully-adjusted GLM, mean blood glucose level was significantly lower among individuals with excellent HL compared with their counterparts with inadequate HL (99.3 vs. 106.0, respectively). Furthermore, the odds for the presence of diabetes in the group of study participants whose HL was "inadequate" were 2.6 times higher $(95 \% \mathrm{Cl}=1.3-5.4)$ compared to those whose HL was "excellent."

Conclusion: We obtained evidence of a strong and significant inverse relationship between measured blood glucose level and $\mathrm{HL}$, independent of many socio-demographic characteristics and measured BMI in a population-based study in a country of the Western Balkans.

Keywords: Albania, blood glucose level, diabetes, health literacy, knowledge

\section{INTRODUCTION}

Health status is largely influenced by health behavior through complex processes involving multichannel multi-layer interactions between individual socio-demographic factors and numerous external factors, influenced and modeled by cognitive skills and internal motivation and attitude toward certain behaviors $(1,2)$. Health literacy $(\mathrm{HL})$, the ability to access, understand, appraise and 
apply health information in order to make appropriate health decisions (3), is often considered as a mediator in the processes leading to specific health behaviors and finally to health status $(2,4)$.

Maintaining the levels of blood glucose within normal range is important to health. As the levels of blood glucose fluctuate greatly during everyday life activities (5), health behavior becomes sensibly relevant for the prevention of diabetes in the general population (6) and especially important in the management of diabetes in terms of diet, physical activity, monitoring blood glucose levels, medication taking, promptly spotting the signs and symptoms of hypoglycemia and hyperglycemia and reducing glucose imbalance risks in general $(7,8)$. Among these, continuous professional and/or regular selfmonitoring of glucose levels is critical for successful diabetes management $(9,10)$ and it is becoming increasingly relevant for the monitoring and prevention of diabetes among healthy and asymptomatic prediabetic population as well, based on recent developments predicting the expansion of use of glucose monitors across all population groups (11).

After the collapse of the communist regime in 1990, Albania is undergoing deep political and socioeconomic reforms which are also associated with changes in the epidemiological profile and health characteristics (12). According to the national Institute of Statistics (INSTAT), life expectancy in Albania in 2018 was 77.4 years in men and 80.5 years in women (13). In Albania, there is an increase of about $45 \%$ in the burden of non-communicable diseases (NCDs) for the period 1990-2017 (14). Yet, the agestandardized burden of NCDs (DALYs per 100,000 population) in Albania in 2017 was lower than in most of the former Yugoslavian Republics, excluding Slovenia (14).

Scientific research has reported significant inverse associations between HL and mean hemoglobin A1c (HbA1c) and mean plasma glucose levels, in both diabetic $(15,16)$ and general population (17), but the evidence about Albania and other transitional countries is scarce.

However, some other studies did not find significant associations of HL with plasma glucose levels and glycemic control $(18,19)$ and a very recent literature review concluded that the association of HL with glycemic control remains inconclusive (20).

In Albania and other Western Balkan countries there are no studies addressing comprehensively the association between $\mathrm{HL}$ and population fasting plasma glucose levels. A previous population-based study conducted in Albania has reported a significant association between HL and body mass index (BMI), irrespective of socio-demographic factors and socio-economic characteristics (21). Albania and other former communist countries in South Eastern Europe are heterogeneous in terms of within-society disease patterns and distribution of health characteristics and conventional risk factors (21). Therefore, it would be interesting to assess potential distinctive features including the magnitude of the relationship between HL and blood glucose level in these transitional societies. In this framework, the aim of our study was to shed light into the association of HL and glucose level in a population-based survey of adult men and women in Albania (21), a country in the
Western Balkans which is currently undergoing tremendous changes and deep reforms in all sectors. More specifically, the objective of our analysis was to assess the independent association of HL and glucose level, adjusting for a full range of demographic factors and socioeconomic characteristics, as well as BMI. This analysis is based on the same study population of a previously conducted study including adult men and women in Albania, which was confined to assessment of the relationship between HL and BMI (21).

\section{METHODS}

\section{Study Design}

This was a cross-sectional study carried out during the period September 2012-February 2014.

\section{Participants and Setting}

The study population included a population-drawn simple random sample of 1,500 adult men and women ( $\geq 18$ years), selected from the registries of family physicians operating in primary health care services of the city of Tirana, which is the capital of Albania. Further details about the study population and the sampling technique are reported elsewhere (21). Overall 1,154 individuals participated in the study (response rate: 88.6\%) (21).

\section{Study Instruments}

Data collection process included measurement of glucose level, BMI and administration of a structured questionnaire to all study participants.

\section{Observed Outcome}

Glucose level was measured by use of a calibrated glucometer (finger stick method, a rapid glucose test kit). Glucose was measured in a fasting state in all study participants (22). In the analysis, normal glucose level was defined as $<100 \mathrm{mg} / \mathrm{dl}$, pre-diabetes as $100-125.9 \mathrm{mg} / \mathrm{dl}$, and diabetes as $\geq 126 \mathrm{mg} / \mathrm{dl}$ (Table 1). These cut-off values are employed in primary health care in Albania for defining possible presence of pre-diabetes and diabetes (22).

\section{Explanatory Factor}

The original full version of the HLS-EU-Q instrument (3) was employed for assessment of HL among study participants. This tool was previously validated in Tirana in 2012 (22). The full version of HLS-EU-Q consists of 47 items measuring different HL dimensions that is access, understanding, appraisal and application of health information in the context of three specific domains: health care (16 items), disease prevention (16 items) and health promotion (15 items) (3).

Each of the HL items assessed the self-perceived difficulty of performing selected health-related tasks on a 4-point scale ranging from very easy (one) to very difficult (four) (3). The items' coding was reversed so that higher scores would indicate better HL (3). Subsequently, for each domain, a summary score was calculated based on scores of the respective items, and a general health index (comprising the scores of all 47 items) was also calculated. Next, the four resulting scores (general HL index, 
TABLE 1 | Distribution of blood glucose level among study participants.

\begin{tabular}{lc}
\hline Variable & Value (mg/dl) \\
\hline Glucose level & 102.67 \\
Mean & 28.76 \\
Standard deviation & 97 \\
Median & $87-110$ \\
Interquartile Range & \\
Glucose level [n (\%)]* & $478(55.8)$ \\
Normal (<100 mg/dl) & $285(33.3)$ \\
Pre-diabetes (100-125.9 mg/dl) & $94(11.0)$ \\
Diabetes ( $\geq 126$ mg/dl) & \\
Glucose level $[\boldsymbol{n}(\%)]$ & $763(89.1)$ \\
No diabetes & $94(11.0)$ \\
Diabetes & \\
\hline
\end{tabular}

*Information about glucose and/or other study variables is missing for 297 individuals.

health care HL, disease prevention HL, and health promotion $\mathrm{HL}$ ) were standardized on a scale ranging from 0 to 50 [using the following formula: index $=($ mean-1) * 50/3, where: "index" is the specified index calculated; "mean" is the average of all items for each individual; " 1 " is the minimal possible value for the mean (leading to a minimum value of the index of 0); " 3 " is the range of the mean; and " 50 " is the chosen maximum value of the new metric], to allow convenient calculations with indices and to simplify comparisons, in line with the recommendations and suggestions of the respective experts involved in the development of this instrument (3).

\section{Confounding Factors}

Anthropometrics included weight (with precision of $100 \mathrm{~g}$ ) which was measured in light clothes using a calibrated beam balance and height (with precision of $1 \mathrm{~mm}$ ) which was measured using a tape attached to the wall with subjects not wearing shoes. BMI was calculated as weight (in $\mathrm{kg}$ ) / height (in $\mathrm{m}^{2}$ ).

Furthermore, data on a full range of socio-demographic and socioeconomic characteristics was collected for all study participants, including age (in the analysis, categorized into: $\leq 25$, $26-45,46-65$, and $\geq 66$ years), sex (men vs. women), marital status (in the analysis, dichotomized into: married vs. single, divorced, and widowed), employment status (dichotomized into: unemployed vs. employed and/or retired), educational attainment $(0-8,9-12$, and $\geq 13$ years), economic status (trichotomized into: very bad/bad, average, and good/very good), and social status (low, middle, and high).

All participants signed an informed consent form after being explained the aims and procedures of the survey. The study was approved by the Albanian Committee of Bio-Medical Ethics on 23 July 2012.

\section{Data Analysis}

For 297 individuals there was missing information on glucose level, BMI or other covariates. These cases were excluded from the analysis; hence, the statistical analysis consisted of 1,154$297=857$ individuals.
Measures of central tendency and dispersion were calculated for the glucose level.

The chi-square test was used to compare the distribution of glucose levels (no diabetes vs. diabetes) according to socio-demographic characteristics (age, sex, marital status, employment, education, and economic and social status), BMI and HL of study participants.

General Linear Model was used to calculate mean values of glucose level among individuals distinguished by different HL categories (inadequate, problematic, sufficient and excellent). Initially, crude (unadjusted) mean values, their $95 \%$ confidence intervals (95\%CIs) and $p$-values were calculated. Next, age-adjusted mean values, 95\%CIs and $p$-values were calculated. Subsequently, general linear models were adjusted for all demographic characteristics (age, sex and marital status). Further adjustment consisted of controlling also for socioeconomic factors (education, employment, social status, and economic status). Finally, BMI was also additionally introduced into the general linear models. Multivariableadjusted mean values of the glucose level, their respective 95\%CIs and $p$-values were calculated.

In addition, binary logistic regression was used to assess the independent association of glucose level (dependent variable, dichotomized into: diabetes vs. no diabetes) with HL levels (inadequate, problematic, sufficient, and excellent). Crude (unadjusted) odds ratios (ORs), their respective 95\% confidence intervals (95\%CIs) and $p$-values were initially calculated. Next, logistic regression models were adjusted for age. Subsequently, all demographic characteristics (age, sex, and marital status) were entered into the logistic models. Subsequently, logistic regression models were additionally adjusted for socioeconomic factors (education, employment, social status, and economic status). Finally, BMI was also introduced into the logistic regression models. Multivariable-adjusted odds ratios ORs, their respective $95 \% \mathrm{CIs}$ and $p$-values were calculated. All analyses met the goodness-of-fit criterion as appraised by the HosmerLemeshow test.

In all cases, a $p \leq 0.05$ was considered as statistically significant.

Statistical Package for Social Sciences (SPSS, version 19.0) was used for all the statistical analyses.

\section{RESULTS}

\section{Description of the Study Group}

On the whole, mean age in this study sample was $45.5 \pm 16.4$ years; $57 \%$ of participants were women; mean years of formal schooling were 12.6 years; about $82 \%$ of study participants perceived themselves as middle class, and about two-thirds (64\%) reported an average economic status (21).

Overall, mean glucose level among study participants was $103 \pm 29 \mathrm{mg} / \mathrm{dl}$ (Table 1). Median value was 97 (interquartile range: 87-110). About one-third of participants exhibited pre-diabetes (100-125.9 mg/dl) upon measurement of glucose level and further $11 \%$ had diabetes $(\geq 126 \mathrm{mg} / \mathrm{dl})$.

Men had a higher prevalence of measured diabetes than women (13 vs. 10\%), but this finding was not statistically 
significant (Table 2). The prevalence of diabetes, as expected, was considerably higher among older participants ( $\geq 66$ years). There was evidence of a graded inverse relationship (although not statistically significant) of diabetes with educational level. Married participants displayed a significantly higher prevalence of diabetes, explained largely by the age difference with the non-married individuals. The prevalence of diabetes was lower among the better-off participants and those with a high social

TABLE 2 | Distribution of blood glucose level by socio-demographic characteristics, $\mathrm{HL}$ and BMl of study participants.

\begin{tabular}{|c|c|c|c|c|}
\hline \multirow[t]{2}{*}{ Variable } & \multirow[t]{2}{*}{ Total } & \multicolumn{2}{|c|}{ Diabetes status } & \multirow[t]{2}{*}{$P$} \\
\hline & & $\begin{array}{c}\text { No diabetes } \\
(n=763)\end{array}$ & $\begin{array}{c}\text { Diabetes } \\
(n=94)\end{array}$ & \\
\hline \multicolumn{5}{|l|}{ Gender } \\
\hline Men & $373(43.5)^{\star}$ & $326(87.4)$ & 47 (12.6) & \multirow[t]{2}{*}{$0.187^{\dagger}$} \\
\hline Women & $484(56.5)$ & 437 (90.3) & $47(9.7)$ & \\
\hline \multicolumn{5}{|l|}{ Age-group } \\
\hline$\leq 25$ years & 113 (13.2) & $113(100.0)$ & $0(-)$ & \multirow{4}{*}{$<0.001$} \\
\hline 26-45 years & $249(29.1)$ & 241 (968) & $8(3.2)$ & \\
\hline $46-65$ years & $388(45.3)$ & $328(84.5)$ & $60(15.5)$ & \\
\hline$\geq 66$ years & 107 (12.5) & $81(75.7)$ & $26(24.3)$ & \\
\hline \multicolumn{5}{|l|}{ Educational level } \\
\hline $0-8$ years & $125(14.6)$ & $107(85.6)$ & $18(14.4)$ & \multirow{3}{*}{0.139} \\
\hline $9-12$ years & $442(51.6)$ & $390(88.2)$ & $52(11.8)$ & \\
\hline$\geq 13$ years & 290 (33.8) & $266(91.7)$ & $24(8.3)$ & \\
\hline \multicolumn{5}{|l|}{ Employment status } \\
\hline Unemployed & 160 (19.2) & $145(90.6)$ & $15(9.4)$ & \multirow[t]{2}{*}{0.257} \\
\hline Employed and/or retired & $672(80.8)$ & $594(88.4)$ & 78 (11.6) & \\
\hline \multicolumn{5}{|l|}{ Marital status } \\
\hline Not married ${ }^{\ddagger}$ & $293(34.8)$ & $272(92.8)$ & $21(7.2)$ & \multirow[t]{2}{*}{0.008} \\
\hline Married & 549 (65.2) & 477 (86.9) & $72(13.1)$ & \\
\hline \multicolumn{5}{|l|}{ Social status } \\
\hline Low & $89(11.1)$ & 80 (89.9) & $9(10.1)$ & \multirow{3}{*}{0.216} \\
\hline Middle & 649 (81.2) & $570(57.8)$ & 79 (12.2) & \\
\hline High & $61(7.6)$ & $58(95.1)$ & $3(4.9)$ & \\
\hline \multicolumn{5}{|l|}{ Economic status } \\
\hline Very bad/bad & 106 (13.2) & $90(84.9)$ & $16(15.1)$ & \multirow{3}{*}{0.047} \\
\hline Average & $527(65.4)$ & $463(87.9)$ & $64(12.1)$ & \\
\hline Good/very good & $173(21.5)$ & $162(93.6)$ & $11(6.4)$ & \\
\hline \multicolumn{5}{|l|}{ BMI } \\
\hline Normal & 288 (33.6) & $272(94.4)$ & $16(5.6)$ & \multirow{3}{*}{$<0.001$} \\
\hline Overweight & 377 (44.0) & 337 (89.4) & 40 (10.6) & \\
\hline Obese & 192 (22.4) & $154(80.2)$ & 38 (19.8) & \\
\hline \multicolumn{5}{|l|}{ Health literacy: } \\
\hline Inadequate & $160(20.0)$ & $128(80.0)$ & $32(20.0)$ & \multirow{4}{*}{$<0.001$} \\
\hline Problematic & 152 (19.0) & 129 (84.9) & $23(15.1)$ & \\
\hline Sufficient & $213(26.7)$ & $190(89.2)$ & 23 (10.8) & \\
\hline Excellent & 274 (34.3) & $259(94.5)$ & $15(5.5)$ & \\
\hline
\end{tabular}

*Absolute numbers and percentages in parentheses (row percentages for the glucose level categories, but column percentages for the totals). Discrepancies in the total numbers are due to the missing values.

${ }^{\dagger} P$-values from the chi-square test.

¥ Single, divorced and widowed. status. There was evidence of a graded relationship with BMI: the prevalence of diabetes was lowest among normal weight individuals (6\%) and highest in obese participants (20\%). Similarly, there was a graded relationship with HL levels: the prevalence of diabetes was lowest among participants with excellent HL (6\%) and highest in those with inadequate HL (20\%) (Table 2).

There was evidence of a mild positive linear association between glucose level and BMI (Spearman's rho = $0.27, P<0.01)$, but a weak inverse correlation with HL (Spearman's rho $=-0.15, P<0.01$ ) (not shown).

TABLE 3 | Association of blood glucose level with HL (General Linear Models).

\begin{tabular}{|c|c|c|c|}
\hline Model & $\begin{array}{c}\text { Mean glucose* } \\
\text { (mg/dl) }\end{array}$ & $95 \% \mathrm{Cl}^{*}$ & $P^{*}$ \\
\hline
\end{tabular}

Model $1^{\ddagger}$

\section{Health literacy}

Inadequate

Problematic

Sufficient

Excellent

Model 2"I

110.9
105.9
102.2
97.7

(10

Health literacy

Inadequate

\section{3}

Problematic $\quad 103.1$

Sufficient

101

Excellent

97.9

$\begin{array}{cc} & <\mathbf{0 . 0 0 1 ( 3 ) ^ { \dagger }} \\ 106.4-115-5 & <0.001 \\ 101.2-110.5 & 0.006 \\ 98.3-106.1 & 0.095 \\ 94.3-101.2 & \text { reference }\end{array}$

Model $3^{\S}$

Health literacy

Inadequate

Problematic

Sufficient

Excellent

Model $4^{\star *}$

Health literacy

Inadequate

Problematic

Sufficient

Excellent

Model $5^{\dagger \dagger}$

$100.8-109.8$

$0.065(3)$

Health literacy

Inadequate

Problematic

Sufficient

Excellent

105.8
103.6
101
98.6

98.5-107.7

0.012

$97.1-104.9$

0.069

0.222

$94.3-101.5$

reference

$0.080(3)$

${ }^{*}$ Mean values, $95 \%$ confidence intervals $(95 \% \mathrm{Cl})$ and $p$-values from the General Linear Models.

tOverall p-value and degrees of freedom (in parentheses).

${ }^{\ddagger}$ Model 1: crude (unadjusted) models.

"Model 2: age-adjusted models.

${ }^{\S}$ Model 3: adjusted for all demographic characteristics (age, sex and marital status).

**Model 4: adjusted for all demographic characteristics and socioeconomic factors (education, employment, social status and economic status).

${ }^{++}$Model 5: adjusted also for BMI. 
TABLE 4 | Association of $\mathrm{HL}$ with blood glucose level; multivariable-adjusted odds ratios (ORs: diabetes vs. no diabetes) from binary logistic regression.

\begin{tabular}{|c|c|c|c|}
\hline Model & OR & $95 \% \mathrm{Cl}$ & $P$ \\
\hline Model $1^{t}$ & & & $<0.001(3)^{*}$ \\
\hline \multicolumn{4}{|c|}{ Health literacy } \\
\hline Inadequate & 4.32 & $2.26-8.26$ & $<0.001$ \\
\hline Problematic & 3.08 & $1.55-6.10$ & 0.001 \\
\hline Sufficient & 2.09 & $1.06-4.11$ & 0.033 \\
\hline Excellent & 1 & Reference & - \\
\hline Model $2^{\ddagger}$ & & & $0.027(3)$ \\
\hline \multicolumn{4}{|c|}{ Health literacy } \\
\hline Inadequate & 2.73 & $1.38-5.44$ & 0.004 \\
\hline Problematic & 2.44 & $1.21-4.95$ & 0.013 \\
\hline Sufficient & 1.88 & 0.94-3.77 & 0.074 \\
\hline Excellent & 1 & Reference & - \\
\hline Model $3^{\text {II }}$ & & & $0.025(3)$ \\
\hline \multicolumn{4}{|c|}{ Health literacy } \\
\hline Inadequate & 2.77 & $1.39-5.49$ & 0.004 \\
\hline Problematic & 2.46 & $1.21-4.99$ & 0.013 \\
\hline Sufficient & 1.84 & 0.92-3.69 & 0.086 \\
\hline Excellent & 1 & Reference & - \\
\hline Model $4^{\S}$ & & & $0.062(3)$ \\
\hline \multicolumn{4}{|c|}{ Health literacy } \\
\hline Inadequate & 2.6 & $1.26-5.37$ & 0.010 \\
\hline Problematic & 2.23 & $1.08-4.62$ & 0.031 \\
\hline Sufficient & 1.67 & $0.82-3.41$ & 0.159 \\
\hline Excellent & 1 & Reference & - \\
\hline Model $5^{\star \star}$ & & & $0.066(3)$ \\
\hline \multicolumn{4}{|c|}{ Health literacy } \\
\hline Inadequate & 2.62 & $1.26-5.44$ & 0.01 \\
\hline Problematic & 2.15 & $1.03-4.48$ & 0.041 \\
\hline Sufficient & 1.65 & $0.80-3.38$ & 0.174 \\
\hline Excellent & 1 & Reference & - \\
\hline
\end{tabular}

* Overall p-value and degrees of freedom (in parentheses).

${ }^{\dagger}$ Model 1: crude (unadjusted) models.

$\ddagger$ Model 2: age-adjusted models.

II Model 3: adjusted for all demographic characteristics (age, sex, and marital status).

$\S$ Model 4: adjusted for all demographic characteristics and socioeconomic factors

(education, employment, social status, and economic status).

${ }^{* *}$ Model 5: adjusted also for BMI.

\section{Results of Univariate Analysis}

Mean unadjusted glucose levels were significantly lower among participants with excellent HL levels compared with those with inadequate HL levels (98 vs. $111 \mathrm{mg} / \mathrm{dl}$ ) (Table 3-model 1).

Conversely, in unadjusted binary logistic regression models (Table 4-model 1), the odds for the presence of diabetes in the group of study participants whose HL was "inadequate" were 4.3 times higher (95\% CI $=2.3-8.3)$ compared to those whose HL was "excellent."

\section{Results of Multivariate Analysis}

In the General Linear Models, adjustment for age (Table 3model 2) and subsequently for all demographic factors (model 3) and further for socioeconomic characteristics (model 4), attenuated somehow the findings. In fully-adjusted models controlling for all socio-demographic factors and BMI (model 5), the difference between the two HL groups nevertheless persisted, with mean glucose levels being significantly lower among participants with excellent HL levels compared with those with inadequate HL levels (99 vs. $106 \mathrm{mg} / \mathrm{dl}$ ). However, the association with "problematic" and "sufficient" HL categories was not statistically significant upon adjustment for all demographic factors, socioeconomic characteristics and BMI (model 5).

In age-adjusted binary logistic regression models (Table 4-model 2) the estimates were attenuated, whereas further adjustment for the other demographic factors (model 3) did not alter the findings. Additional adjustment for socioeconomic characteristics (model 4) slightly attenuated the estimates. In fully-adjusted models (Table 4-model 5), the odds for the presence of diabetes in the group of study participants whose HL was "inadequate" were 2.6 times higher (95\% CI = 1.3-5.4) compared to those whose HL was "excellent."

\section{DISCUSSION}

In this population-based sample of adult men and women in transitional Albania, we obtained evidence of a significant inverse association between measured blood glucose level and HL, which was assessed based on a well-established international instrument already validated in Albania (22). The inverse association between glucose level and HL was strong, consistent and persisted upon adjustment for a whole range of sociodemographic characteristics and measured BMI.

Our findings, in general, are in line with previous reports from international research.

A study among 228 individuals aged 30 years or older and seeking care at emergency department of a hospital in Georgetown, Guyana, reported that mean blood glucose level was higher among lower HL subjects $(128.3 \mathrm{mg} / \mathrm{dl})$ compared to high HL subjects (117.1 mg/dl), but the difference was not statistically significant (17). In our study we reported a lower overall mean glucose level $(102.67 \mathrm{mg} / \mathrm{dl})$. Nevertheless, the inverse association between HL and plasma glucose levels evidenced in our survey replicated rather similarly the finding of the Guyana study (17). In our survey, this association held true and significant even after controlling for potential confounding effects of basic sociodemographic and socioeconomic factors.

In a population-based study of elderly people aged 70-79 years, there was a reverse significant association between health literacy and mean fasting blood glucose among women, but not in men (23). Overall, these results are similar to those reported by our survey.

Our findings are also compatible with another populationbased study including 1817 Japanese individuals (24).

Evidence of significant and inverse associations between health literacy and fasting plasma glucose is provided by another recent paper reporting on the associations of HL with an array of laboratory parameters among individuals aged 23-88 years receiving health checkup in Taipei, Taiwan (25). 
Previous publications about this study population (among 1,154 individuals) in Albania have revealed inverse and significant associations of mean health literacy score with age, education and low social and economic status (21). Also, low $\mathrm{HL}$ individuals (inadequate and problematic $\mathrm{HL}$ ) were about two times more likely to be overweight/obese compared to excellent HL participants in this population group (26). Findings from international literature also highlight such associations of HL with age, social status and economic status $(3,27)$ and overweight/obesity $(28,29)$. Since the proportion of prediabetic and diabetic individuals in our study was higher among these groups at high risk of low health literacy then we assume that all these factors play a role in the observed HL-glucose association.

Besides fasting plasma glucose levels we also reported about the prevalence of prediabetes $(33.3 \%)$ and diabetes $(11 \%)$ in this study population group. We found that diabetes prevalence (including prediabetes and diabetes individuals) was higher among married individuals and it was significantly and positively associated with age, but inversely associated with economic status, body mass index (BMI) and health literacy. Prediabetes is considered a high-risk condition for progression to full diabetes as one-quarter of affected persons will develop it in the next 5 years and more than two-thirds will do so in their lifetime (30). Prediabetes also increases the risk of diabetic complications and cardiovascular disease among those experiencing it compared to normal glucose level individuals (30).

According to Centers for Disease Control and Prevention (CDC) the prevalence of prediabetes among American adults aged $\geq 18$ years was $33.9 \%$ in 2015 (31). The prevalence of prediabetes varies according to the definition (cut-offs) used (30). With regard to diabetes prevalence, it was $12.2 \%$ among US adults aged $\geq 18$ years; diabetes prevalence increased with age and peaked at age $\geq 65$ years with $25.2 \%$ (32). These prevalence rates are very similar to our findings. International Diabetes Federation reported that in 2019 the prevalence of diabetes in Albania among people aged 20-79 years was 9\% with another $43 \%$ estimated to have undiagnosed diabetes (33). A study among 381 Saudi adult males aged 18-60 years reported that the prevalence of prediabetes and diabetes was 9.2 and $27.6 \%$, respectively (34), illustrating the effect of using different cut-off values in the prevalence of these conditions.

Prevalence rate of prediabetes and diabetes vary according to different factors including education level, social and economic status, prevalence of overweight and obesity, access to healthcare services, etc. $(30,34,35)$. We didn't find a significant gender difference regarding diabetes prevalence in our study even though the diabetes prevalence was higher in men than in women (12.6 vs. $9.7 \%$, respectively), a finding not congruent with previous reports (36). On the other hand, women seem to be more aware about their diabetic status, more inclined to be treated and more likely to have controlled glycemic level compared to men according to a large study among individuals aged $\geq 18$ years China (36). This finding is also supported by previous reports about the same population group in Albania suggesting that women exhibit higher proportions of excellent HL compared to men, possibly due to the higher and more frequent contacts of women with the health care system and their higher engagement in family issues (26). These elements could play a role in the lower prevalence of diabetes among women in Albania and could merit further scientific pursuit.

In our study population we reported that being married was significantly associated with a higher prevalence of diabetes, a finding supported by international research (34). Another study reported a higher prevalence of diabetes among married individuals only in crude unadjusted analysis but the association turned non-significant upon simultaneous controlling of confound effects (37). A large study among adults aged $\geq 18$ years in Florida also reported that the prevalence of diabetes was significantly higher among married individuals in crude analysis but not in multivariable adjusted models (35). The authors of this paper also provided a conceptual model representing significant predictors of prediabetes and diabetes based on their findings, generally stating that age and sex affect diabetes directly and indirectly through mixed and parallel effects on income level, physical activity, BMI, various health conditions such as hypertension, arthritis and hypercholesterolemia all finally contributing to prediabetes and diabetes; furthermore, each of these factors, besides age and sex, also interact with eachother and in addition they affect directly the development of prediabetes and or diabetes (35).

The association of inadequate $\mathrm{HL}$ and diabetes is also supported by international literature $(38,39)$, with limited health literacy being quite prevalent about diabetic patients. A systematic review reported that the prevalence of limited health literacy among type 2 diabetes patients varied from about $7 \%$ in Switzerland to $82 \%$ in Taiwan (40). Basically, health literacy affects health outcomes (including diabetes outcomes) through acquisition of new knowledge, positive attitudes, greater self-efficacy and behavior change, obviously depending on individual reading fluency and prior knowledge and affected by prevailing cultural norms (39). In general low health literacy among diabetic patients is associated with worse diabetes knowledge, worse self-efficacy and self-care behaviors, worse glycemic control, increased risk of hypoglycemic events, increased likelihood of diabetes complications, etc. $(38,39)$.

Given the unfavorable position of low HL diabetic patients, it is necessary to pinpoint strategies and interventions that would help overcome this barrier. Such efforts include specifically tailored toolkits, guides or use of new online technologies intended to facilitate patient-provider communication (39). Other interventions could target health system and health institutions in order to modify them and facilitate their interaction of low health literacy patients (41). Education-based strategies, training about management of blood pressure and glucose-lowering medication, are also shown to improve diabetes outcomes among patients with limited health literacy (38).

Policymakers, decision makers and health professionals need to be aware about these effective and beneficial strategies, the application of which could facilitate the interaction of low health literacy patients and individuals with the health system.

There are some potential limitations of this study including the possibility of selection bias, information bias, timeline of 
the study and its cross-sectional design. On the whole, the response rate of this study was high (89\%), but for 297 individuals there was no valid information on covariates including blood glucose level. In addition, at best, findings from this study can be generalized to the adult population of Tirana only given the fact that the survey was confined to this region. Blood glucose level and BMI were objectively assessed in all participants, which is reassuring. However, one measurement is not sufficient to establish the diagnosis of diabetes and, usually, other parameters are used (2-h Oral Glucose Tolerance Test [OGTT] and HbAlc testing) - posing another limitation of this study. Also, the instrument for assessment of HL was based on a well-developed and standardized tool (3) previously validated in the Albanian context (22). On the face of it, there is no reason to assume a differential reporting of HL between individuals with diabetes and their counterparts without diabetes. Yet, the possibility of information bias cannot be ruled out completely, particularly for the self-reported socioeconomic factors. Of note, the data used for the current analysis is more than 5 years old, which is another limitation of this study. Lastly, cross-sectional associations are not assumed to be causal and, therefore, the relationship between blood glucose level and HL should be more vigorously determined in future prospective studies.

In conclusion, regardless of these potential limitations, we obtained evidence of a strong and significant inverse relationship between measured blood glucose level and HL, independent of many socio-demographic characteristics and measured BMI

\section{REFERENCES}

1. Hessler DM, Fisher L, Polonsky WH, Bowyer V, Potter M. Motivation and attitudes toward changing health (MATCH): a new patient-reported measure to inform clinical conversations. J Diabetes Complicat. (2018) 32:6659. doi: 10.1016/j.jdiacomp.2018.04.009

2. Sun X, Shi Y, Zeng Q, Wang Y, Du W, Wei N, et al. Determinants of health literacy and health behavior regarding infectious respiratory diseases: a pathway model. BMC Public Health. (2013) 13:261. doi: 10.1186/1471-2458-13-261

3. HLS-EU Consortium. Comparative report of health literacy in eight EU member states. The European Health Literacy Survey HLS-EU. (Second revised and extended version, date July 22th, 2014) (2012) (Available online at: https://cdn1.sph.harvard.edu/wp-content/uploads/sites/135/2015/ 09/neu_rev_hls-eu_report_2015_05_13_lit.pdf (accessed January 17, 2020).

4. van der Heide I, Wang J, Droomers M, Spreeuwenberg P, Rademakers J, Uiters E. The relationship between health, education, and health literacy: results from the dutch adult literacy and life skills survey. J Health Commun. (2013) 18 (Suppl. 1):172-84. doi: 10.1080/10810730.2013.825668

5. Freckmann G, Hagenlocher S, Baumstark A, Jendrike N, Gillen RC, Rössner $\mathrm{K}$, et al. Continuous glucose profiles in healthy subjects under everyday life conditions and after different meals. J Diabetes Sci Technol. (2007) 1:695703. doi: $10.1177 / 193229680700100513$

6. Tuso P. Prediabetes and lifestyle modification: time to prevent a preventable disease. Perm J. (2014) 18:88-93. doi: 10.7812/TPP/14-002

7. Ausili D, Barbaranelli C, Rossi E, Rebora P, Fabrizi D, Coghi C, et al. Development and psychometric testing of a theory-based tool to measure self-care in diabetes patients: the self-care of diabetes inventory. BMC Endocr Disord. (2017) 17:66. doi: 10.1186/s12902-017-0218-y

8. Coppola A, Sasso L, Bagnasco A, Giustina A, Gazzaruso C. The role of patient education in the prevention and management of type 2 diabetes: an overview. Endocrine. (2016) 53:18-27. doi: 10.1007/s12020-015-0775-7 in a population-based sample of adult men and women in a post-communist country.

In the context of current uncertainty prevailing in the international literature about the relationship between HL and blood glucose level, the present survey conducted in transitional Albania adds to the body of literature that supports a significant association between HL and fasting plasma glucose levels.

\section{DATA AVAILABILITY STATEMENT}

The datasets generated for this study are available on request to the corresponding author.

\section{ETHICS STATEMENT}

The studies involving human participants were reviewed and approved by Albanian Committee of Bio-Medical Ethics. The patients/participants provided their written informed consent to participate in this study.

\section{AUTHOR CONTRIBUTIONS}

$\mathrm{GB}, \mathrm{HB}$, and ET contributed to the study conceptualization and design, analysis, and interpretation of the data. QD wrote the first draft of the article. MD and DT commented comprehensively on the manuscript. All authors have read and approved the submitted manuscript.

9. Vigersky R, Shrivastav M. Role of continuous glucose monitoring for type 2 in diabetes management and research. J Diabetes Complicat. (2017) 31:2807. doi: 10.1016/j.jdiacomp.2016.10.007

10. Culleton JL. Preventing diabetic foot complications. Tight glucose control and patient education are the keys. Postgrad Med. (1999) 106:74-8, 83. doi: 10.3810/pgm.1999.07.601

11. Hall H, Perelman D, Breschi A, Limcaoco P, Kellogg R, McLaughlin T, et al. Glucotypes reveal new patterns of glucose dysregulation. PLoS Biol. (2018) 16:e2005143. doi: 10.1371/journal.pbio.2005143

12. Burazeri G, Goda A, Sulo G, Stefa J, Kark JD. Financial loss in pyramid saving schemes, downward social mobility and acute coronary syndrome in transitional Albania. J Epidemiol Commun Health. (2008) 62:6206. doi: 10.1136/jech.2007.066001

13. Institute of Statistics, Albania. Socio-Demographic Indicators of the Albanian Population. Available online at: http://instat.gov.al/al/temat/treguesitdemografik\%C3\%AB-dhe-social\%C3\%AB/popullsia/\#tab2 (accessed June 17, 2020).

14. Institute for Health Metrics and Evaluation. Global Health Data Exchange. Available online at: http://ghdx.healthdata.org/gbd-results-tool (accessed June 17, 2020).

15. Alvarez PM, Young LA, Mitchell M, Blakeney TG, Buse JB, Vu MB, et al. Health literacy, glycemic control, and physician-advised glucose self-monitoring use in type 2 diabetes. Diabetes Spectr. (2018) 31:3447. doi: $10.2337 / \mathrm{ds} 17-0064$

16. Olesen K, Reynheim ALF, Joensen L, Ridderstråle M, Kayser L, Maindal HT, et al. Higher health literacy is associated with better glycemic control in adults with type 1 diabetes: a cohort study among 1399 Danes. BMJ Open Diabetes Res Care. (2017) 5:e000437. doi: 10.1136/bmjdrc-2017-000437

17. McNaughton CD, Korman RR, Kabagambe EK, Wright SW. Health literacy and blood glucose among guyanese emergency department patients without diagnosed diabetes: a cross-sectional study. Diabetol Metab Syndr. (2015) 7:31. doi: 10.1186/s13098-015-0028-1 
18. Al Sayah F, Majumdar SR, Egede LE, Johnson JA. Associations between health literacy and health outcomes in a predominantly low-income african american population with type 2 diabetes. J Health Commun. (2015) 20:5818. doi: 10.1080/10810730.2015.1012235

19. Morris NS, MacLean CD, Littenberg B. Literacy and health outcomes: a cross-sectional study in 1002 adults with diabetes. BMC Fam Pract. (2006) 7:49. doi: 10.1186/1471-2296-7-49

20. Dahal PK, Hosseinzadeh H. Association of health literacy and diabetes self-management: a systematic review. Aust J Prim Health. (2019) 25:52633. doi: 10.1071/PY19007

21. Toçi E, Burazeri G, Myftiu S, Sørensen K, Brand H. Health literacy in a population-based sample of adult men and women in a South Eastern European country. J Public Health (Oxf). (2016) 38:6-13. doi: 10.1093/pubmed/fdv006

22. Bregu A, Toçi E, Rrumbullaku L, Muja H, Roshi E, Burazeri G. Prevalence of diabetes mellitus in a population-based sample of adults in Tirana, Albania. BJMMR. (2014) 4:852-61. doi: 10.9734/BJMMR/2014/5611

23. Quartuccio M, Simonsick EM, Langan S, Harris T, Sudore RL, Thorpe $\mathrm{R}$, et al. The relationship of health literacy to diabetes status differs by sex in older adults. J Diabetes Complicat. (2018) 32:368-72. doi: 10.1016/j.jdiacomp.2017.10.012

24. Yokokawa H, Fukuda H, Yuasa M, Sanada H, Hisaoka T, Naito T. Association between health literacy and metabolic syndrome or healthy lifestyle characteristics among community-dwelling Japanese people. Diabetol Metab Syndr. (2016) 8:30. doi: 10.1186/s13098-016-0142-8

25. Cheng YL, Shu JH, Hsu HC, Liang Y, Chou RH, Hsu PF, et al. High health literacy is associated with less obesity and lower framingham risk score: sub-study of the VGH-HEALTHCARE trial. PLoS ONE. (2018) 13:e0194813. doi: 10.1371/journal.pone.0194813

26. Toçi E, Burazeri G, Kamberi H, Toçi D, Roshi E, Jerliu N, et al. Health literacy and body mass index: a population-based study in a South-Eastern European country. J Public Health (Oxf). (2019) doi: 10.1093/pubmed/fdz103. [Epub ahead of print].

27. Sørensen K, Van den Broucke S, Fullam J, Doyle G, Pelikan J, Slonska Z, et al. (HLS-EU) Consortium health literacy project European. Health literacy and public health: a systematic review and integration of definitions and models. BMC Public Health. (2012) 12:80. doi: 10.1186/1471-2458-12-80

28. Husson O, Mols F, Fransen MP, van de Poll-Franse LV, Ezendam NP. Low subjective health literacy is associated with adverse health behaviors and worse health-related quality of life among colorectal cancer survivors: results from the profiles registry. Psychooncology. (2015) 24:478-86. doi: 10.1002/pon.3678

29. Wolf MS, Feinglass J, Thompson J, Baker DW. In search of 'low health literacy': threshold vs. gradient effect of literacy on health status and mortality. Soc Sci Med. (2010) 70:1335-41. doi: 10.1016/j.socscimed.2009.12.013

30. Hostalek U. Global epidemiology of prediabetes - present and future perspectives. Clin Diabetes Endocrinol. (2019) 5:5. doi: 10.1186/s40842-019-0080-0

31. CDC. Centers for Disease Control and Prevention. Prevalence of Prediabetes. (2019). Available online at: https://www.cdc.gov/diabetes/data/statisticsreport/prevalence.html (accessed January 18, 2020).
32. CDC. Centers for Disease Control and Prevention. Prevalence of Both Diagnosed and Undiagnosed Diabetes. (2019). Available online at: https:// www.cdc.gov/diabetes/data/statistics-report/diagnosed-undiagnosed.html (accessed January 18, 2020).

33. IDF. International Diabetes Federation: IDF Diabetes Atlas - 9th ed. Brussels: International Diabetes Federation (2019).

34. Aldossari KK, Aldiab A, Al-Zahrani JM, Al-Ghamdi SH, Abdelrazik M, Batais MA, et al. Prevalence of prediabetes, diabetes, and its associated risk factors among males in saudi arabia: a population-based survey. J Diabetes Res. (2018) 2018:2194604. doi: 10.1155/2018/2194604

35. Okwechime IO, Roberson S, Odoi A. Prevalence and predictors of pre-diabetes and diabetes among adults 18 years or older in florida: a multinomial logistic modeling approach. PLoS ONE. (2015) 10:e0145781. doi: 10.1371/journal.pone.0145781

36. Yue J, Mao X, Xu K, Lü L, Liu S, Chen F, et al. Prevalence, awareness, treatment and control of diabetes mellitus in a Chinese population. PLoS ONE. (2016) 11:e0153791. doi: 10.1371/journal.pone.0153791

37. Ramezankhani A, Azizi F, Hadaegh F. Associations of marital status with diabetes, hypertension, cardiovascular disease and allcause mortality: a long term follow-up study. PLoS ONE. (2019) 14:e0215593. doi: 10.1371/journal.pone.0215593

38. Bailey SC, Brega AG, Crutchfield TM, Elasy T, Herr H, Kaphingst K, et al. Update on health literacy and diabetes. Diabetes Educ. (2014) 40:581604. doi: 10.1177/0145721714540220

39. Cavanaugh KL. Health literacy in diabetes care: explanation, evidence and equipment. Diabetes Manag (Lond). (2011) 1:191-9. doi: 10.2217/ dmt. 11.5

40. Abdullah A, Liew SM, Salim H, Ng CJ, Chinna K. Prevalence of limited health literacy among patients with type 2 diabetes mellitus: a systematic review. PLoS ONE. (2019) 14:e0216402. doi: 10.1371/journal.pone. 0216402

41. Gazmararian JA, Beditz K, Pisano S, Carreón R. The development of a health literacy assessment tool for health plans. $J$ Health Commun. (2010) 15 (Suppl. 2):93-101. doi: 10.1080/10810730.2010.4 99986

Conflict of Interest: The authors declare that the research was conducted in the absence of any commercial or financial relationships that could be construed as a potential conflict of interest.

The reviewer TS declared a past co-authorship with one of the authors GB to the handling Editor.

Copyright (C) 2020 Dika, Duli, Burazeri, Toci, Brand and Toci. This is an open-access article distributed under the terms of the Creative Commons Attribution License (CC $B Y)$. The use, distribution or reproduction in other forums is permitted, provided the original author(s) and the copyright owner(s) are credited and that the original publication in this journal is cited, in accordance with accepted academic practice. No use, distribution or reproduction is permitted which does not comply with these terms. 